\title{
Life Cycle Cost Methodology for Mixers based on MTTF Life Cycle Cost Model
}

\author{
Sagar D. Ghagare ${ }^{1}$, Prof. Abhijeet S. Suryawanshi ${ }^{2}$, Vishal D Jadhav ${ }^{3}$ \\ PG Student, Mechanical Engg. Dept, ADCET Ashta, India ${ }^{1}$ \\ Assistant Professor, Mechanical Engg. Dept, AGTI's DACOE Karad, India ${ }^{2}$ \\ Assistant Professor, Mechanical Engg. Dept, AITRC, Vita, India ${ }^{3}$
}

\begin{abstract}
Most of the manufacture and mixer users have confusion about selecting the life cycle cost model or life cycle costing of mixers. This paper presents the life cycle costing of mixers based on the MTTF life cycle cost model from the various life cycle cost models. This method or model can also be applied to the static as well as dynamic mixers. This model has five components and these components will be easily collected by the manufacturer data and field data from the end users of the mixers. MTTF life cycle cost model has benefitted to manufacturer and also users to calculating the total life cycle cost of their products.
\end{abstract}

Keywords: Life cycle cost, Mixers, Life cycle costing, Life cycle cost model.

\section{INTRODUCTION}

Many terms and definitions are used in the area of life cycle costing. The life cycle cost of a system may be defined simply as the sum of all costs incurred during its life span (i.e., the total of acquisition and ownership costs) [1]. LCC includes all costs incurred from the point at which decision is made to acquire a system through the operational life, to the eventual disposal of the system or product. The term life cycle costing was used for the first time in 1965 in a report entitled "Life Cycle Costing in Equipment Procurement" [2]. This report was prepared by the Logistics Management Institute, Washington, D.C., for the assistant secretary of defence for installations and logistics, U.S. Department of Defence, Washington, D.C.

The objective of LCC analysis is to choose the most cost effective approach from a series of alternatives so the least long term cost of ownership is achieved while considering cost elements which include design, development, production, operation, maintenance, support, and final disposition of a major system over its anticipated useful life span. LCC is the sum of acquisition, logistic support and operating expenses. LCC is the language of money. LCC analysis helps engineers justify equipment and process selection based on total costs rather than the initial purchase price as the cost of operation, maintenance, and disposal costs exceed all other costs many times over [3]. Mixing is avery important unit operation in any chemical process industry, for instance, all operations involving blending, homogenization, emulsion, preparation, extraction, liquid phase reaction, etc. need mixing in one form to another. Broadly, two types of commercial mixing devices are available, that are static and dynamic mixers. Selection of an efficient agitation will depend on the nature of liquid, operation, condition and intensity of circulation and shear [4]. We should apply the same LCC model to both the static and dynamic mixture to calculate the LCC of them. The demands low lifecycle cost of the mixers and hence a mixer is selected for the analysis in order to reduce the LCC and improve the overall profits of the users by reducing the LCC mixers.

\section{LIFE CYCLE COST}

The life cycle cost of every system/product can be divided into four stages, namely system/product design, production operations and finally retirement. System design can be defined as decision making process that determines the system configuration and reliability and maintainability of the system/subsystem/products, where the goal is to build a system that performs all functions successfully through its life. While functional requirements are easy to capture and quantify, the performance requirements that depend upon reliability, maintainability is not specified explicitly by most of the customers. Apart from the designing for quality, reliability and maintainability, it is also methods necessary for control and assurance be used at the production stage.

After the production stage, the product or system used by the customers, where maintenance and support play a major role. It is this stage of the product life cycle that determines the competitiveness of the product in the market. If a product is designed with due consideration to issues related to support, maintenance, service delivery, and competence and capability of users, it can be a major source of revenue for the manufacturer and users[5]. LCC analysis provides an input in deciding between alternative designs, replacing aging equipment, making purchasing comparisons between equipment, developing operations and support concepts, maintenance methods and preparing 
IARJSET

logistic support plans. Over the entire life of product one comes across the cost elements such as initial costs, installation and commissioning, operation and maintenance costs, failure and support costs, environmental costs and disposal costs. Fig 1 shows Major cost elements of LCC.

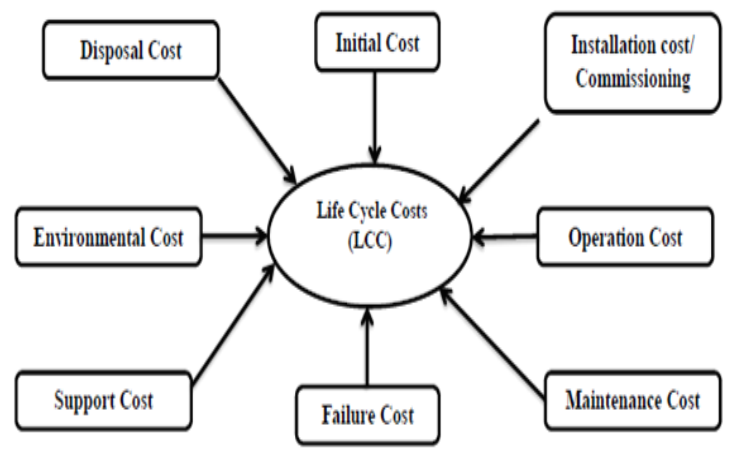

Fig 1. Major cost components of LCC

Life cycle costs refer to all costs associated with the acquisition and ownership of a product or a system over its full life. Decision made during conceptual and preliminary design will affect total life cycle cost. About 80 percent of the life cycle costs has been set at the design phase only. Once the product is designed and put into service it is almost impossible to reduce the LCC [6].

\section{LIFE CYCLE COSTING}

The LCC procedure is well developed and documents in the Military Handbook [7] and Society of Automotive Engineers 1993[8].Life cycle costing is increasingly being used in the industrial sector around the world to make various types of decisions that directly or indirectly concern engineering equipment and systems/products[1].

There could be many reasons for this upward trend, such as

- Competition;

- Increasing operation and maintenance costs;

- Budget limitations;

- Expensive products or systems (e.g., military systems, space systems, and aircraft);

- Rising inflation; and

- Increasing awareness of cost effectiveness among product, equipment, and system users.

To perform Life Cycle Cost analysis the following steps should be executed as shown in fig. 2 .

The main goal of life cycle costing is to get the maximum benefit from limited resources. Management plays a key role in making life cycle costing a worthwhile effort.The availability of good data is very important for good life cycle cost estimates. The life cycle cost model must include all program-related costs.

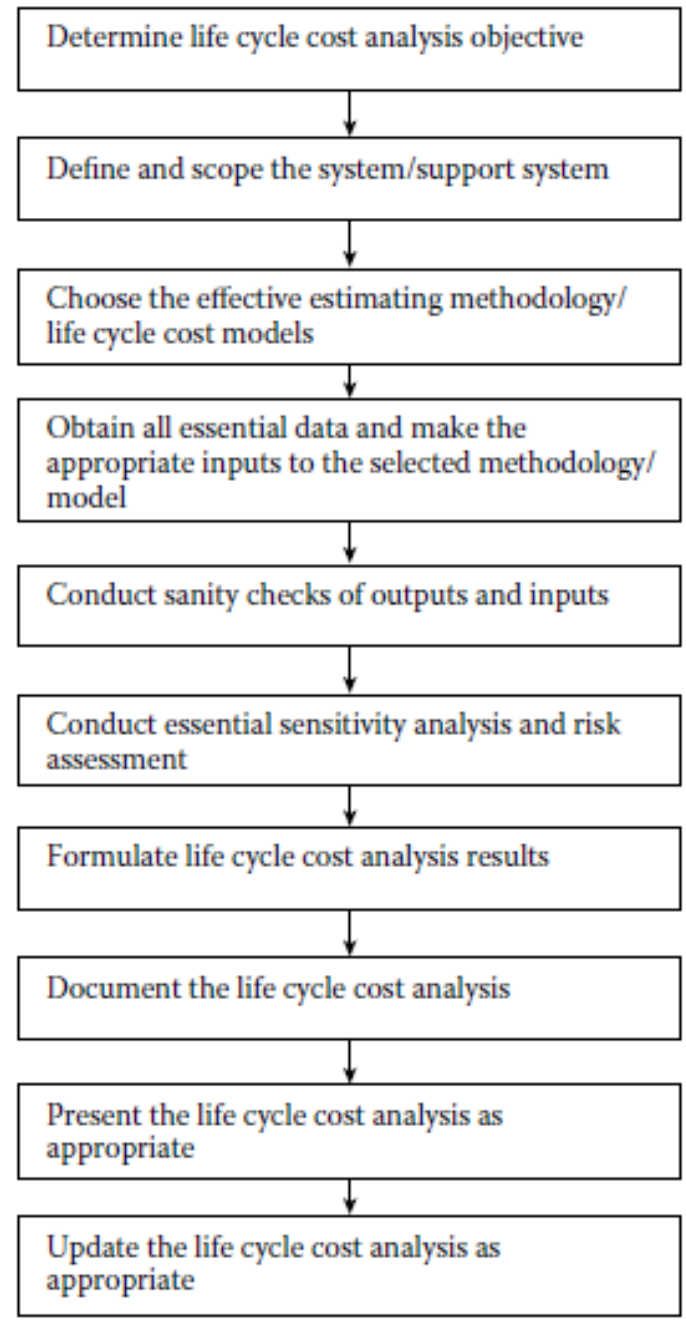

Fig.2. Steps for performing life cycle cost analysis

\section{LIFE CYCLE COST MODELS}

Life cycle cost models are used to compute LCC of engineering systems. A specific LCC model may be useful to compute LCC of certain systems, but may not be useful for another system due to non-availability of data in a specified cost format. Selected model must address both the acquisition and operation \&maintenance cost elements, and must allow sensitivity analysis based on reliability parameters, in order to obtain valid LCC impacts.

There are several LCC models reported in published literature such as the General life cycle cost model, Department of energy life cycle cost model, Life cycle model based on MTTF, Software life cycle cost model, Health care facilities life cycle cost model, Appliance life cycle cost model, LCC model used by hydraulic Institute, SAE model, etc. [9]. From those LCC models, LCC model based on MTTF is one of the well know model for the life cycle costing of static as well as dynamic mixers. This life cycle cost model has five cost components such as acquisition costs, operating costs, failure costs, support costs and net salvage value(Disposal cost). 
IARJSET

International Advanced Research Journal in Science, Engineering and Technology

National Conference on Design, Manufacturing, Energy \& Thermal Engineering (NCDMETE-2017)

AGTI's Dr. Daulatrao Aher College Engineering, Vidyanagar Extension, Karad

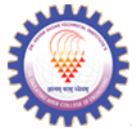

Vol. 4, Special Issue 1, January 2017

\section{LCC OF MIXERS}

The selection of the LCC model depends on the availability of the data. From this various LCC models available life cycle model based on MTTF is selected for the mixers. This life cycle cost model has five cost components such as acquisition costs, operating costs, failure costs, support costs and net salvage value. The acquisition cost takes into account management cost, engineering design and manufacturing, material costs, production costs, engineering data, spare parts and logistics, initial training and service during warranty period etc. Operating cost includes power consumption and the cost of coolent. The cost associated with the failure of the component and its maintenance is considered as failure cost. This cost values will collected by the manufacturer collected cost and users collected cost by field data. Failure costs consist of system downtime, labor charges, part replacement cost, and logistic cost. Support cost includes preventive maintenance cost. It consists of labor cost and part replacement cost. At the end of useful life, the mixers are scraped. This value is considered as net salvage value.

\section{A) Acquisition costs}

The acquisition cost of the mixer/productaccounts for the development cost, engineering design and material costs, testing, packaging and logistics, and service during warranty period, qualification and certification, product modification cost, etc.

Acquisition cost generally expressed as follows: $\mathrm{Cu}=$ Design and development cost +Material Cost + assembly cost+ Testing cost + Packaging cost + others (Profit charges + Transportation cost + warranty Cost + Documentation + Certification, etc.)

The acquisition cost is the easily identifiable element in the life cycle cost of mixer LCC analysis or any product/system. The work related to estimation of product acquisition cost is abundant.

\section{B) Operating costs}

The main cost drives associated with the operating cost of mixers, the cost of energy and labour cost for operating mixers and coolent cost for use for the mixer. So we can estimate the operating cost of mixer as follows:

$$
\text { Operating cost, } \mathrm{Co}=\mathrm{t}\left[\mathrm{C}_{\mathrm{en}}+\mathrm{C}_{\mathrm{c}}+\mathrm{C}_{\mathrm{lh}}\right]
$$

\section{C) Failure costs}

The maintenance and repair cost is estimated as the sum of the costs of preventive and corrective maintenance cost. The cost of preventive maintenance is estimated as the sum of the cost of the components to be replaced during the preventive maintenance while corrective maintenance costs are estimated based on the expected number of failures in a given interval. So the failure costs are known asthe corrective maintenance cost.The MTTF is estimated mixer/product .Labor charges for repair areconsidered per hour.
Annual failure cost $=($ failures per year $*$ repair hours $*$ activity cost $)+$ part cost + logistic cost

Expected failure cost over the life $=\mathrm{td} / \mathrm{MTBF}$

Failure cost of the mixers over the entire life will be expressed as,

Failure cost, $\mathrm{C}_{\mathrm{f}}=$ Total failure cost/ Expected failure cost

The failure cost of the mixers or system will change with event, time and conditions. Also the difference between manufacturer and user calculated failure costs of the same product.

\section{D) Support costs}

Preventive maintenance costs can be considered as support costs. The annual preventive maintenance costs may comprise the labor cost associated with the preventive maintenance and the cost of components that are replaced during preventive maintenance. In addition, there are fixed support costs of documentation and tooling cost required in regard to the maintenance practices.

The support cost of the mixers is calculates as the sum of fixed documentation cost and annual preventive maintenance cost while preventive maintenance cost calculated based on the mean maintenance hour into labor cost per hour. So the support cost of the mixer can be calculated as,

The support cost, $\mathrm{Cs}=$ fixed support cost $+($ annual mean hour $\mathrm{x}$ labor charge per hour + part cost)

\section{E) Net salvage value}

Net salvage value is also known as the disposal cost.The mixer disposal strategy can be recycling, reusing or disposing off the individual components of the mixer. At the end of useful life of the mixers when scrapped, the approximate net salvage value is S. Often the disposal value of the mixer is always the negative value in the LCC of mixers.

\section{F) Life cycle cost}

The costs estimated for the various elements making up the total life cycle costs need to be summation of all components. There are also financial factors to take into consideration in developing the LCC. The life cycle cost of the mixer is expressed as,

Life cycle cost $=$ Acquisition costs + Operational costs + Failure cost - Net salvage value

Where,

Net salvage value $=$ Salvage value - Disposal cost mathematically,

$\mathrm{LCC}=\mathrm{Cu} . \mathrm{N}+[\mathrm{Fo}+\mathrm{PA}(\mathrm{i}, \mathrm{td}) \mathrm{Co} . \mathrm{N}]+[\mathrm{PA}(\mathrm{i}, \mathrm{td}) \mathrm{Cf}$ to $/$ MTTF.N $]+\left[F_{s}+\right.$ PA (i, td) Cs.N] - [PF (i, td) S.N]

Where,

$\mathrm{Cu}=$ Acquisition cost of agitator motor

$\mathrm{N}=$ Number of machines to be procured

Fo $=$ Fixed cost of operating

$\mathrm{Co}=$ Annual operating cost per unit

$\mathrm{F}_{\mathrm{S}}=$ Fixed support cost

$\mathrm{Cs}=$ Annual support cost per unit 
IARJSET

$\mathrm{Cf}=$ Cost per failure

to $=$ Operating hours per unit per year

$\mathrm{S}=$ Unit salvage value

to $/ \mathrm{MTTF}=$ The expected number of failures per year

$\mathrm{PF}(\mathrm{i}, \mathrm{td})=$ Single present value

PA $(\mathrm{i}, \mathrm{td})=$ Annuity factor

$\mathrm{td}=$ Design life in years

For an interest rate of $\mathrm{m} \%$ and economical life of $n$ years, the single present value is estimated as below,

$$
\operatorname{PF}\left(\mathrm{i}, \mathrm{t}_{\mathrm{d}}\right)=1 /(1+\mathrm{m})^{\mathrm{n}}
$$

Where,

$\mathrm{PF}=$ the future amount at the end of years $n$

The annuity factor converts equal annual payments over $n$ years to a single present day equivalent amount[10]. For an interest rate of $\mathrm{m} \%$ and an economical life of $\mathrm{n}$ years, it can be calculated as,

$$
\operatorname{PA}\left(i, t_{d}\right)=\left[(1+i)^{n}-1\right] /\left[i(1+i)^{n}\right] .
$$

\section{CONCLUSION}

The life cycle cost analysis methodology in this paper has been carried out for mixers and this methodology will be applied to the other system/subsystem/products. LCC is a powerful tool of economic analysis, but in order to perform effective life cycle cost analysis of mixers, the LCC must possess skill in many areas, including engineering, statistical analysis, reliability and maintainability engineering, logistics and contracting. The analysis of LCC, the field data and cost of components are necessary for exact calculations of LCC, because of absence of failuredata, and cost of components, often analysis performed formally and incorrectly. The studied methodology useful to enhance the LCC of mixers. The documented methodology in this paper can also use in reliability growth and LCC analysis of high power mixture.

\section{REFERNCES}

1. B.S.Dhillon, "Life Cycle Costing for Engineers", ISBN 978-1-43981688-2.

2. Logistics Management Institute, "Life Cycle Costing in Equipment Procurement".

3. H. Paul Barringer, "Life Cycle Cost \& Reliability for Process Equipment", 8th Annual ENERGY WEEKConference \& Exhibition, January 28-30, 1997.

4. M. V. Joshi, "Process Equipment Design", Chapter 14, pp 371-404.

5. Bhupesh Kumar Lad and M. S. Kulkarni, "Integrated reliability and optimal maintenance schedule design: a Life Cycle Cost based approach", Int. J. Product lifecycle Management Vol.3, No.1, 2008.

6. L. Y. Waghmode and S. G. Joshi, "A Suggested Integrative Approach for Minimizing Product Life Cycle Costs Using Product Life Cycle, Design cycle and Life Cycle Design Methodologies", National Conference on Design for Product life cycle, Feb 1718,2006, BITS Pilani.

7. MIL-HDBK-259, Military Handbook, Life Cycle Cost in Navy Acquisitions, 1 April 1983, available from Global Engineering Documents, phone 1-800-854-7179.

8. Society of Automotive Engineers (SAE) 1993, Reliability and Maintainability Guideline for Manufacturing Machinery and Equipment, Warrendale, PA.
9. Logistics Management Institute, "Life Cycle Costing in Equipment Procurement".

10. H. Paul Barringer, "Life Cycle Cost Tutorial", Fifth International Conference on Process Plant Reliability, October 2-4, 1996. 